\title{
Análise de políticas editoriais de periódicos científicos nacionais: Contribuições para o Boletim do Museu Paraense Emílio Goeldi. Ciências Humanas
}

\section{Jimena Felipe Beltrão ${ }^{I}$}

http://orcid.org/0000-0002-2333-3495

\section{Taíse da Cruz Silva ${ }^{I I}$}

http://orcid.org/0000-0002-1185-3717

I Museu Paraense Emílio Goeldi, PA, Brasil.

Ph.D em Ciências Sociais pela University of Leicester, Inglaterra.

${ }^{I I}$ Museu Paraense Emílio Goeldi, PA, Brasil.

Graduação em Biblioteconomia pela Universidade Federal do Pará.

http://dx.doi.org/10.1590/1981-5344/3301

Este artigo analisa políticas editoriais de periódicos científicos nacionais indexados na SciELO (Scientific Electronic Library Online) nas áreas de Antropologia, Arqueologia e Linguística com objetivo de identificar semelhanças e diferenças em comparação à atual política editorial do Boletim do Museu Paraense Emílio Goeldi. Ciências Humanas. O intuito da pesquisa é recomendar eventuais ajustes à atual política editorial do periódico centenário do Museu Paraense Emílio Goeldi. A pesquisa adotou abordagem quali-quantitativa com uso de técnicas documental e bibliográfica para a coleta de dados. As variáveis analisadas nos documentos das políticas editoriais foram: os idiomas em que são aceitas as submissões; os formatos dos originais: se impresso ou eletrônico; as seções em que se subdividem os conteúdos 
publicados; o processo de avaliação por pares; os requisitos para constituição de autoria; a origem dos conteúdos publicados; os critérios de acesso aos conteúdos publicados; a indexação dos periódicos em bases de dados nacionais e internacionais; e a política de deteç̧ão de plágio. O exame comparativo desses elementos demonstrou a eficiência das normas e instruções em vigor no Boletim ao mesmo tempo em que indicou a necessidade de detalhamento do escopo da revista quando se trata das áreas correlatas, caso de disciplinas como Sociologia, Geografia e outros.

Palavras-chave: Boletim do Museu Paraense Emílio Goeldi; Ciências Humanas; Periódico científico; Política editorial.

\section{Editorial policies in national scientific journals: contribution for the Boletim do Museu Paraense Emílio Goeldi. Ciências Humanas}

This article analyzes the editorial policies of Brazilian periodicals indexed in the SCIELO electronic library in the fields of anthropology, archaeology, and linguistics in order to identify similarities and differences between these journals and the Boletim do Museu Paraense Emílio Goeldi. Ciências Humanas and subsequently recommend potential adjustments to current editorial policy at this journal. The survey was qualitative and quantitative, and used documentary and bibliographic techniques to collect the data. The variables analyzed were languages for submissions, journal format (online or printed), sections in which content is presented, peer review methods, requirements for authorship, content origin (from dissertations or other research), access to content, indexing in Brazilian and international databases, and plagiarism detection policy. The authors determined that 
all the elements of the Boletim's current policy are effective, but recommend more precise definition of the journal's scope for works in correlated areas (such as sociology and geography).

Keywords: Boletim do Museu Paraense Emílio Goeldi; Human Sciences; Scientific journal; Editorial policy.

Recebido em 05.10.2017 Aceito em 24.08.2020

\section{Introdução}

O Boletim do Museu Paraense Emílio Goeldi. Ciências Humanas (ISSN 2178-2547 online) é um periódico científico de acesso aberto, condição essa que democratiza o conhecimento. Com mais de 120 anos de existência, uma das mais antigas publicações do seu gênero em contínua circulação, o periódico oferece acesso gratuito ao conteúdo de suas publicações em nível mundial compatível com princípios de uma ciência compartilhada como descreve Packer, para quem "o acesso aberto ao conhecimento científico ocorre por meio da publicação dos resultados da pesquisa científica na web, sem barreiras de acesso." (PACKER, 2011, p. 36).

Em 2016, o Boletim iniciou um processo de disponibilização em formato exclusivamente digital. Sobre os aspectos do formato eletrônico no qual o Boletim passou a ser apresentado, observa-se que:

A automatização representa a possibilidade de agilizar o processo editorial, medida compatível com a reduzida equipe editorial e com a necessidade de redução de custos. A iniciativa se reveste de significado adicional, pois trata-se também de medida de caráter sustentável pela redução considerável do volume de papel utilizado na apresentação e circulação de originais. (ALENCAR; BELTRÃo, 2016, p. 3).

O meio digital também levou a que, hoje, as submissões sejam feitas em plataforma eletrônica, o que, entre outros aspectos, agiliza o processamento editorial, tendo em vista que: 
Publicações independentes encontrarão mais vantagens na adoção integral do [ScholarOne]. Poderão, através dele, não apenas gerenciar o processo editorial, mas também efetuar a publicação na Internet em site com interface de usuário configurável e amigável, com suporte para vários idiomas selecionáveis [...] (TRZESNIAK, 2009, p. 100).

O Boletim tem sido objeto de inúmeros estudos (BELTRÃO; SILVA, 2019; BELTRÃO et. al., 2019; BELTRÃO; SILVA, 2018; BENCHIMOL; ARRUDA; SILVA, 2016; PAIVA; RAMALHO; CARVALHO, 2015; BENCHIMOL; PINHEIRO, 2014; FIGUEIREDO, 2007; SOUSA, 2006). Um estudo anterior se dedicou a identificar os principais conteúdos publicados no Boletim dentre os volumes da coleção disponíveis na página do periódico na internet:

Em um momento de transição para um formato digital e um processo editorial baseado em recursos tecnológicos que se impõem e vêm auxiliar na agilização das etapas de tratamento de material inédito e seu alcance de esferas de compartilhamento do conhecimento científico, considera-se importante atualizar os dados oriundos de estudos prévios [...] (ALENCAR; BELTRÃO, 2016, p. 2).

Ao eleger os itens mais relevantes para a análise e possível revisão da política editorial do Boletim do Museu Paraense Emílio Goeldi, será possível avançar na direção da melhoria da compreensão da atuação do periódico, sua área de abrangência, escopo. Nesse sentido, a definição de política editorial consiste em:

[...] escolha do título e subtítulo do periódico, a área de conhecimento abrangida e o projeto editorial da publicação - no qual são descritos a sua missão, periodicidade, avaliação por pares, critérios de arbitragem, exigências de originalidade dos artigos, seções, idiomas, perfil de autores e leitores, requisitos normativos e dados sobre a circulação da publicação. (GRUSZYNSKI; GOLIN; CASTEDO, 2008, p. 10).

O claro delineamento de critérios facilita ainda mais o trabalho de editores, avaliadores, redatores, revisores, designers, dentre tantos profissionais envolvidos no processo editorial, já que: 


\begin{abstract}
À política editorial [...] cabe definir a abrangência temática mais ou menos extensa, dependendo das áreas do conhecimento previstas nos planos da organização, levando-se em conta suas relações com o local ou região do país ou do mundo, as influências recíprocas e as responsabilidades sociais assumidas (BUFREM, 2009, p. 28).
\end{abstract}

Aqui se propôs uma investigação que examinasse políticas editoriais de periódicos científicos nacionais indexados na Scientific Electronic Library Online (SciELO) e dedicados às Ciências Humanas com ênfase nas áreas de Antropologia, Arqueologia e Linguística. De caráter qualiquantitativo, o estudo se utiliza de duas técnicas de coleta de dados, quais sejam, a bibliográfica e a documental e tem por objetivo analisar e comparar semelhanças e diferenças entre a atual política editorial do Boletim e as políticas editoriais daquelas publicações. Com esse exercício, haverá a possibilidade de serem identificadas questões editoriais que envolvam a recomendação de eventuais ajustes à atual política do periódico do Museu Paraense Emílio Goeldi.

\title{
2 Metodologia
}

Em etapa exploratória da pesquisa, realizada entre os dias 01/12/2016 e 24/01/2017, foi efetuada busca na Web adotando como critério de seleção os títulos que disponibilizassem suas políticas editoriais. Nessa fase foram identificadas doze revistas nacionais e internacionais. No mesmo período foram pesquisadas ainda as revistas nacionais indexadas na SciELO relativas às áreas de Antropologia, Arqueologia e Linguística, resultando na identificação de quatro títulos para Antropologia, quatro títulos para Linguística e um registro para área de Arqueologia.

Adicionalmente às buscas na Web e na SciELO, empreendeu-se levantamento junto ao Arquivo Guilherme de La Penha (ARQ) do Museu Paraense Emílio Goeldi (MPEG)'considerando que os documentos são "[...] a essência de uma organização, a memória de uma sociedade." (MERLO; KONRAD, 2015, p. 27). Nesse espírito, a pesquisa documental em acervos de instituições como o Museu Goeldi possibilitou investigar os registros, descobrir e desvendar a história institucional e a trajetória editorial do periódico ${ }^{1}$. No Arquivo do MPEG foram localizados documentos relativos a políticas editoriais anteriores do Boletim. Observou-se, em documentos datados a partir da década de 1980, a preocupação da comissão editorial em nomear profissionais qualificados para atuar na disseminação do conhecimento científico referente à Amazônia.

\footnotetext{
${ }^{1}$ Dentre os documentos levantados no Arquivo Guilherme de La Penha (ARQ) do MPEG, constam itens de circulação interna relativos às atividades da unidade responsável pelo Boletim em cada época: memorandos, atas, ordens internas, entre outros.
} 
As variáveis mapeadas nos documentos que detalhavam as políticas editoriais foram: o idioma das submissões; formatos dos originais e seções do periódico; processo de revisão por pares; requisitos e credenciais para autores; origem dos manuscritos submetidos; critérios de acesso ao conteúdo; indexação em bases de dados nacionais e internacionais; e política de detecção de plágio.

\section{Resultados e discussão}

\subsection{Idiomas}

O levantamento na SciELO revelou que as revistas científicas selecionadas para análise, a exemplo do Boletim, aceitam colaborações em diversos idiomas como o português, 0 inglês, o espanhol e o francês. Para Pinheiro;Bräscher e Burnier (2005), o periódico científico representa papel fundamental na comunicação científica, sendo o idioma em que o artigo é publicado um entre os critérios de avaliação das publicações científicas. Ainda que o Boletim aceite, como a maioria dos periódicos estudados, submissões em quatro línguas, identificou-se que, nos últimos dez anos, o Boletim apresentou "[...] 82 por cento de artigos publicados em português." (BELTRÃO et al., 2019, p. 187), enquanto os artigos em inglês representaram $14 \%, 3 \%$ em espanhol e apenas $1 \%$ em francês (BELTRÃO et al., 2019).

Dentre as revistas científicas pesquisadas, apenas a Delta: Revista de Documentação de Estudos em Linguística Teórica e Aplicada e a ALFA: Revista de Linguística publicam trabalhos também em italiano. A relevância dos idiomas dos artigos publicados está em seu potencial de internacionalização como indicam Padilha et al. (2014), que enfatizam que, como critério de internacionalização, o periódico científico deve ser publicado no mínimo em dois idiomas, sendo um deles o inglês. Assim a "questão do idioma se torna relevante no cenário digital. Quanto mais idiomas diferentes o periódico aceita, maior 0 grau de internacionalização." (RODRIGUES; OLIVEIRA, 2012, p. 87).

\subsection{Os formatos e as seções}

As publicações analisadas estão disponíveis em dois formatos: o impresso e o eletrônico. A publicação científica impressa é definida como:

Um dos tipos de publicações seriadas, que apresenta sob a forma de revistas, boletim, anuário etc., editada em fascículos com designação numérica e/ou cronológica, em intervalos pré-fixados (periodicidade), por tempo indeterminado, com a colaboração, em 
geral, de diversas pessoas, tratando de assuntos diversos, dentro de uma política editorial definida, e que é objeto de Número Internacional Normalizado (ISSN). (ASSOCIAÇÃO BRASILEIRA DE NORMAS TÉCNICAS, 2003, p. 2).

Já os periódicos científicos eletrônicos são aqueles que disponibilizam informações científicas em meio digital, ou seja, "[...] periódicos aos quais se tem acesso mediante 0 uso de equipamentos eletrônicos." (MUELLER, 2000a, p. 78).

No que tange aos suportes, doze dentre os títulos analisados estão disponíveis tanto no formato impresso como no eletrônico, como se observa no Quadro 1, enquanto que oito títulos só oferecem a versão eletrônica (Quadro 2). O Boletim, por sua vez, publicou versões impressa e eletrônica até 2015, mas a partir de 2016 está disponível apenas em versão eletrônica.

Quadro 1 - Periódicos publicados em versões impressa e eletrônica

\begin{tabular}{|l|}
\hline - Horizontes Antropológicos \\
\hline - Mana \\
\hline - Revista de Antropologia \\
\hline - Tempo Social \\
\hline - ALFA: Revista de Linguística \\
\hline $\begin{array}{l}\text { - DELTA: Documentação de Estudos em Lingüística Teórica e Aplicada (desde } 2011 \text { publica } \\
\text { apenas a versão online) }\end{array}$ \\
\hline - Trabalhos em Linguística Aplicada \\
\hline - Ambiente construído (de início a revista era impressa, mas hoje publica apenas a versão online) \\
\hline - Ciência da Informação \\
\hline - Revista Mexicana de Ciencias Políticas y Sociales \\
\hline - Revista Encuentros \\
\hline - Pensar: Revista de Ciência Jurídica (UNIFOR) \\
\hline
\end{tabular}

Fonte: Dados coletados pelos autores.

Quadro 2 - Periódicos publicados apenas em versão eletrônica

\begin{tabular}{|l|}
\hline - Revista Brasileira de Linguística Aplicada \\
\hline - Revista Nera: Núcleo de Estudos, Pesquisas e Projetos de Reforma Agrária \\
\hline - Encontros Bibli \\
\hline -Revista Política Hoje \\
\hline -Race \\
\hline -Comunicación y Medios \\
\hline - Revista Inter Scientific \\
\hline -Vocesenel Fénix \\
\hline
\end{tabular}

Fonte: Dados coletados pelos autores. 
As seções identificadas nos títulos examinados recebem contribuições originais na forma de artigos científicos, relatos de pesquisa, resenhas bibliográficas, entre outros. O Boletim do Museu Paraense Emílio Goeldi. Ciências Humanas aceita: artigos científicos, artigos de revisão, notas de pesquisa, memória, debate, resenhas bibliográficas e teses e dissertações. Em geral, as seções dos periódicos científicos são definidas "[...] pelo editor e comissão editorial e devem constar das normas da revista, de forma a orientar, claramente, autores e editores." (PINHEIRO; BRÄSCHER; BURNIER, 2005, p. 32). Para as autoras os artigos de um periódico científico são considerados o núcleo e as demais seções são complementares.

Dentre as diversas seções encontradas nos periódicos sob investigação, destaca-se uma seção denominada "Espaço Aberto", mantida pela revista Horizontes Antropológicos, destinada à publicação de trabalhos que não estejam de acordo com o tema e escopo do periódico. Chamadas com temas livres são recurso comum dentre muitos periódicos da área das Ciências Humanas. No caso do Boletim, com temas específicos são publicados dossiês.

\subsection{Revisão por pares}

Uma outra categoria de análise se dedicou à revisão por pares, que identificou que a maioria dos títulos opta pelo sistema "duplo cego" (double-blind review), tendo em vista que "esse procedimento [...] evita influenciar a decisão do árbitro na apreciação do trabalho, [...][já que] não revela o nome do autor para o avaliador nem o nome do avaliador para o autor" (STUMPF, 2008, p. 24).Quanto ao sistema de avaliação, sabe-se que:

O processo de revisão por pares, revisão paritária ou arbitragem (peer review ou refereeing, em inglês), é um procedimento utilizado para avaliação dos manuscritos submetidos às revistas científicas. Os trabalhos são encaminhados para dois ou mais especialistas da área, preservando-se o anonimato do autor. Os revisores fazem comentários e oferecem sugestões para melhorias e podem, também, reprovar o trabalho. (SABADINI; SAMPAIO; NASCIMENTO, 2009, p. 54, grifo dos autores).

Tanto o Boletim como as revistas científicas estudadas adotam o sistema de avaliação por pares (peer review) e exigem no mínimo o parecer positivo de dois avaliadores para os artigos serem aprovados; em caso de um parecer favorável e de outro contrário, o trabalho científico é 
encaminhado a um terceiro avaliador. Deste modo, "cada componente do processo realiza suas atividades para que o editor possa chegar a um veredicto final [...] publique-se, publique-se após revisão, ou não se publique." (STUMPF, 2008, p. 20).

O periódico Encontros Bibli: Revista Eletrônica de Biblioteconomia e Ciência da Informação difere dos demais títulos no que tange ao número de pareceres: os artigos originais e os ensaios são avaliados por três pareceristas que pertencem ao comitê editorial da revista, enquanto que as resenhas são encaminhadas para a avaliação de dois pareceristas. A revisão pelos pares é decisiva, uma vez que "[...] a confiabilidade é [...] uma das características mais importantes da ciência, pois a distingue do conhecimento popular não científico." (MUELLER, 2000b, p. 18). Por ser um veículo de comunicação científica formal, cabe ao periódico científico fornecer informação legítima e de qualidade à comunidade científica.

\subsection{Autoria}

Considerando a variável autoria como o "[...] local reservado às pessoas ou entidades que de alguma forma deram uma contribuição original e assumiram responsabilidades pelo trabalho apresentado" (SABADINI; SAMPAIO; KOLLER, 2009, p. 121) constatou-se, entre os periódicos examinados, a existência de títulos que não restringem a autoria das submissões a indivíduos com grau de doutor. Mas há divergência sobre o título máximo exigido dos autores: há periódicos que não exigem o grau de doutor aos primeiros autores. Sobre exigência dessa natureza, recomenda-se priorizar "[...] autores com maior maturidade científica e trabalhos com impacto sobre o campo científico da revista." (FERREIRA, 2005, p. 273 apud COSTA; GUIMARÃES, 2010, p. 88). Entretanto, Costa e Guimarães (2010) criticam essa sugestão e argumentam que esse fato favorece e prioriza autores que sejam doutores. Outros autores também contestam:

[...] esta ideia, ao ressaltarem que, apesar de editores de periódicos ficarem satisfeitos em publicar artigos de autores com boa reputação precisam se conscientizar de que muitos artigos serão de autores cujos nomes não atraem nenhuma atenção particular. A avaliação de qualidade dos artigos, portanto deve ser baseada no próprio mérito, o qual se refere a oito fatores, nomeadamente: originalidade e inovação; reconhecimento dos trabalhos anteriores; relevância para o corpo de conhecimentos da área; objetividade; escrita clara; qualidade dos argumentos; implicações teóricas e práticas; estar de acordo com os objetivos editoriais do periódico. (CALVERT; ZENGZHI, 2001 apud COSTA; GUIMARÃES, 2010, p. 88). 
O Boletim não discrimina autoria pelo grau acadêmico do indivíduo seja ele primeiro ou único autor. A aprovação do artigo não está condicionada a este atributo mas sim ao cumprimento das normas de publicação contidas na política editorial, que se encontra disponível em seu site http://www.museu-goeldi.br/editora/humanas/\#. Já as revistas Ciência da Informação, ALFA: Revista de Linguística, Revista Brasileira de Linguística Aplicada e Trabalhos em Linguística Aplicada exigem que os autores devem ter, no mínimo, os títulos de mestre/mestrando ou doutor/doutorando. Encontros Bibli: Revista Eletrônica de Biblioteconomia e Ciência da Informação, por sua vez, recomenda que, preferencialmente, pelo menos um dos autores seja doutor. Quanto a autoria única e coautoria, levantamento realizado entre 2006 e 2015 no Boletim do Museu Paraense Emílio Goeldi. Ciências Humanas demonstrou que "[...] no período de dez anos estudados, o número de autores e coautores que publicaram artigos no Boletim. Ciências Humanas somam 432 [...]". (BELTRÃO et al., 2019, p. 185).

\subsection{Origem dos manuscritos submetidos}

As publicações examinadas na pesquisa diferem nesse aspecto. A Revista Brasileira de Linguística Aplicada e o periódico Ambiente Construído aceitam artigos científicos resultantes de pesquisa de mestrado ou doutorado, entretanto recomendam que o nome do orientador conste em nota de rodapé e não como coautor A RACE: Revista de Administração, Contabilidade e Economia da FUNDACE, por outro lado, aceita artigos publicados em anais de congressos e eventos, desde que em conformidade com os critérios da revista para esse tipo de publicação. Já a Revista Nera: Núcleo de Estudos, Pesquisas e Projetos de Reforma Agrária informa que, em casos específicos, o conselho editorial pode julgar a republicação de textos já disponíveis em outros países, mas que apresentem destacada contribuição conforme a linha editorial. Opção similar se registra na revista Ciência da Informação, que, excepcionalmente, aceita trabalhos que já tenham sido publicados em periódicos estrangeiros. No Boletim, há casos de publicação de textos clássicos relevantes nas áreas-foco e ainda não disponíveis, por exemplo, em português².

Ainda de acordo com o levantamento realizado nas edições do Boletim do Museu Paraense Emílio Goeldi. Ciências Humanas entre 2006 a 2015, identificamosverificaram-se nos Dados Internacionais de Catalogação as palavras-chave dos artigos publicados relativas a

\footnotetext{
${ }^{2}$ Ver Almeida e Rocha (2016).
} 
identificando exemplos ${ }^{3}$ de interdisciplinaridade (BELTRÃO et al., 2019) e também exemplos de autores que utilizaram conteúdos de teses e dissertações para produzir artigos aceitos para publicação no Boletim ${ }^{4}$. O detalhamento do conteúdo dos artigos aceitos, incluindo a especificação de temas, assuntos, tópicos e origem desses conteúdos, poderá auxiliar os autores na tomada de decisão ao submeter sua produção ao Boletim do Museu Paraense Emílio Goeldi. Ciências Humanas.

Em qualquer hipótese, no caso dos periódicos indexados na SciELO,

A responsabilidade pelo conteúdo dos periódicos é dos autores e dos editores, conforme acordos estabelecidos entre as partes. O programa SciELO não assume nenhuma responsabilidade legal relacionada com os conteúdos publicados pelos periódicos. (SCIENTIFIC ELECTRONIC LIBRARY ONLINE, 2014, p. 20).

\subsection{Política de acesso}

Todos os periódicos científicos analisados na pesquisa adotam o acesso aberto. O movimento de acesso aberto à informação científica age de forma a garantir a disponibilização gratuita do conteúdo da revista. Para Bomfá e outros (2008), promover o acesso gratuito e a disseminação da informação científica é da mais alta importância sobretudo para editores, autores, pesquisadores, bibliotecários e profissionais da informação. Dizem os autores:

Os movimentos em favor do acesso livre à informação científica surgiram a partir de discussões entre pesquisadores, bibliotecários, autores e editores com o intuito de promover a divulgação e acesso, de modo rápido e amplo, às publicações de literatura científica

3Na área da Sociologia: BARGAS, Janine de Kássia; CARDOSO, Luís Fernando Cardoso. Cartografia social e organização política das comunidades remanescentes de quilombos de Salvaterra, Marajó, Pará, Brasil. Boletim do Museu Paraense Emílio Goeldi. Ciências Humanas, Belém, v. 10, n. 2, p. 469-488, maio/ago. 2015; e CARNEIRO, Marcelo Sampaio. Da certificação para as concessões florestais: organizações não govemamentais, empresas e a construção de um novo quadro institucional para o desenvolvimento da exploração florestal na Amazônia brasileira. Boletim do Museu Paraense Emílio Goeldi. Ciências Humanas, Belém, v. 6, n. 3, p. 525-541, set./dez. 2011. Na área da História: HENRIQUE, Márcio Couto. Entre o mito e a história: o padre que nasceu índio e a história de Oriximiná. Boletim do Museu Paraense Emílio Goeldi. Ciências Humanas, Belém, v. 10, n. 1, p. 47-64, jan./abr. 2015.

4 RICCI, Magda Maria de oliveira; MAFRA, Alessandra Regina e Souza. Do Folclorismo à História da Cultura na Amazônia: o percurso construído por Vicente Salles. Boletim do Museu Paraense Emilio Goeldi. Ciências Humanas, Belém, v. 12, n. 1, p. 221-240, jan./abr. 2017; e SQUEFF, Letícia. A Grand Tour de um brasileiro: a importância da Itália nas ideias de Manuel de Araújo Porto-Alegre. Boletim do Museu Paraense Emilio Goeldi. Ciências Humanas, Belém, v. 12, n. 2, p. 377-387, maio/ago. 2017. 
primaria. Além disso, tem-se o aumento da visibilidade, tanto nacional quanto internacional, dos resultados das pesquisas científicas. (BOMFÁ et al., 2008, p. 311).

Outro aspecto relevante da política de acesso aberto em periódicos científicos eletrônicos diz respeito a "[...] um modelo em que taxas de assinaturas e de acesso não são cobradas dos leitores, além do que os direitos autorais permanecem com os autores." (GUMIEIRO; COSTA, 2012, p. 104). É unânime entre as revistas científicas averiguadas o não pagamento de taxas, entretanto a Ambiente Construído cobra dos autores serviços de revisão ortográfica e gramatical executados por profissionais credenciados.

\subsection{Indexação em bases de dados nacionais e internacionais}

Existem vários tipos de sistemas de recuperação da informação: bases de dados, diretórios, índices, portais de periódicos e até catálogos. Essas formas de acesso aumentam a visibilidade e a disseminação da informação científica no mundo. Além disso, a "internet tornou a pesquisa mais rápida e a informação acessível a pessoas localizadas em diferentes partes do mundo, aumentando ainda mais a importância da indexação dos periódicos em bases de dados conceituadas em suas áreas [...]" (OLIVEIRA, 2005, p. 36).

No caso da SciELO, as revistas científicas credenciadas são automaticamente indexadas em bases de dados nacionais e internacionais, dentre elas: SCOPUS ELSEVIER, Directoryof Open Access Journals(DOAJ); EBSCO e Red de Revistas Cientificas de America Latina y el Caribe, España y Portugal (Redalyc). Quanto aos 12 títulos localizados na web, nove estão disponíveis em fontes de prestígio para a comunidade científica, tais como:Directoryof Open Access Journals(DOAJ), Portal de Periódicos da CAPES e SCOPUS, entre outros, enquanto três títulos não fornecem informações de indexação (Quadro 3).

Quadro 3 -Indexação das revistas localizadas na web

\begin{tabular}{|l|c|c|c|c|}
\hline \multicolumn{1}{|c|}{ PERIÓDICOS } & DOAJ & CAPES & SCOPUS & $\begin{array}{c}\text { Outros } \\
\text { sistemas de indexação }\end{array}$ \\
\hline - Ambiente construído & Sim & Sim & Sim & Sim \\
\hline - Ciência da Informação & Sim & Sim & Sim & Sim \\
\hline $\begin{array}{l}\text { - Comunicación y Medios } \\
\text { (Universidad de Chile) }\end{array}$ & Não & Não & Não & Não \\
\hline - Encontros Bibli & Sim & Sim & Sim & Sim \\
\hline $\begin{array}{l}\text { - Pensar: Revista de Ciência Jurídica } \\
\text { (UNIFOR) }\end{array}$ & Sim & Sim & Sim & Sim \\
\hline
\end{tabular}




\begin{tabular}{|l|c|c|c|c|}
-Race & Sim & Sim & Sim & Sim \\
\hline - Revista Encuentros & Sim & Sim & Sim & Sim \\
\hline $\begin{array}{l}\text { - Revista Inter Scientific (Universidad } \\
\text { Interamericana de Puerto Rico) }\end{array}$ & Não & Não & Não & Não \\
\hline - Revista Política Hoje & Sim & Sim & Sim & Sim \\
\hline $\begin{array}{l}\text { - Revista Mexicana de Ciencias } \\
\text { Políticas y Sociales }\end{array}$ & Sim & Sim & Sim & Sim \\
\hline $\begin{array}{l}\text { - Revista Nera: Núcleo de Estudos, } \\
\text { Pesquisas e Projetos de Reforma } \\
\text { Agrária }\end{array}$ & Sim & Sim & Sim & Não \\
\hline $\begin{array}{l}\text {-Voces em el Fénix (Universidad de } \\
\text { Buenos Aires) }\end{array}$ & Não & Não & Não & \\
\hline
\end{tabular}

Fonte: Dados coletados pelos autores.

O Boletim do Museu Paraense Emílio Goeldi. Ciências Humanas está disponível em sete bases de dados internacionais: Anthropological Index Online; Anthropological Literature; Citas Latinoamericanas en Ciencias Sociales y Humanidades (CLASE); International Bibliography of the Social Sciences (IBSS); Sistema Regional de Informaciónen Línea para Revistas Científicas de América Latina, el Caribe, España y Portugal (LATINDEX), SCOPUS ELSEVIER e na Rede de Revistas Científicas Latinoamericana (Redalyc), além de estar disponível na Scientific Electronic Library Online (SciELO), uma plataforma nacional que promove ampla visibilidade do conteúdo publicado.

\subsection{Política de detecção de plágio}

Um tema da maior relevância e que protege a Ciência e seus produtores da falta de ética de indivíduos que insistem em copiar textos alheios, o plágio também foi alvo do presente estudo. Autores definem o plágio como: "Ato ou efeito de plagiar apresentação feita por alguém, como de sua própria autoria, de trabalho, obra intelectual etc. produzido por outrem." (HOUAISS; VILLAR; FRANCO, 2004, p. 2.232).

Como estratégia de proteção contra o plágio, o Boletim utiliza recursos como CrossRef/Ithenticate, entre outros disponíveis na Web. Nesse contexto, é relevante mencionar a Revista Mexicana de Ciencias Políticas y Sociales, identificada na Web, que faz constar em sua política editorial quatro exemplos de rejeição, aplicáveis tanto ao formato impresso como ao eletrônico, em todos os idiomas publicados pela revista: a) se o texto integral do artigo já foi publicado em outro periódico; b) quando extensos fragmentos de materiais previamente publicados são parte do texto submetido à revista; c) quando há conteúdo ou memórias publicadas na íntegra.

São inúmeras as formas de faltar com a ética editorial. Spinak (2013) compreende, por exemplo, que o autoplágio é uma delas e se 
configura quando o autor reutiliza ou publica algo de sua própria autoria que já esteja acessível, sem informar a referência.

\section{Conclusões e recomendações}

Detentor de uma política editorial consolidada e indexado em bases de dados nacionais e internacionais, o periódico Boletim do Museu Paraense Emílio Goeldi. Ciências Humanas ratifica sua contribuição científica e atuação como veículo de comunicação científica formal indispensável na Amazônia. A classificação A1, concedida pela Coordenação de Aperfeiçoamento de Pessoal de Nível Superior (CAPES) através do WebQualis no quadriênio (2013-2016) a todas as áreas-foco do Boletim- Antropologia, Arqueologia, Letras e Linguística - é prova disso. A relevância dessa conceituação decorre de ser considerado como "[...] um critério de qualidade do periódico, pois essa avaliação é feita por especialistas da área sobre periódicos nos quais pesquisadores nacionais publicam artigos científicos." (OLIVEIRA, 2005, p. 37).

As principais diferenças encontradas na análise proposta pelo estudo correspondem aos idiomas, à autoria e ao tipo de manuscritos aceitos. Com base nas diferenças que, de fato, podem constituir elementos para a revisão da política editorial do Boletim, seguem-sealgumas considerações visando efetuar ajustes no documento que orienta e define o escopo e as normas do periódico.

O Boletim é publicação institucional vinculada à Coordenação de Pesquisa e Pós-Graduação (COPPG) do MPEG. Com uma diversidade tanto entre os autores como entre as disciplinas, o periódico amplia as fontes de conhecimento, permitindo perspectivas diferenciadas ao tempo que podem ser complementares no exercício de produção do conhecimento. $O$ escopo do periódico, que compreende a Antropologia, a Arqueologia e a Linguística, admitindo áreas correlatas, caso da Sociologia, da Museologia, da História, do Turismo, da Religião, da Comunicação e Letras entre outras, pode ser descrito de forma a auxiliar a compreensão de potenciais autores sobre os temas e assuntos aceitos para publicação.

A política editorial em vigor atende às necessidades da revista, o que se confirma pela sua indexação em bases nacionais e internacionais e pela sua avaliação no estrato A1 do WebQualis da CAPES para o quadriênio 2013-2016 nas suas principais áreas do conhecimento: Antropologia, Arqueologia e Linguística. Com periodicidade regular, o Boletim do Museu Paraense Emílio Goeldi. Ciências Humanas é periódico quadrimestral.

Como resultado da análise comparativa entre a política editorial do Boletim e a de outros periódicos, recomendamos a revisão no que se refere ao escopo, em proposta que ofereça detalhamento de que conteúdo a revista publica. Essa medida vai garantir submissões mais coerentes 
com os princípios do Boletim. Especial atenção deve ser conferida às áreas correlatas do Boletim como as disciplinas: Sociologia, História, Turismo, Religião entre outras. Um aprofundamento da descrição dos conteúdos que configuram as áreas afins à Antropologia, à Arqueologia e à Linguística facilitará e esclarecerá potenciais autores. A definição de como apresentar resultados produzidos, por exemplo, em pesquisas desenvolvidas em nível de mestrado e doutorado é outra medida essencial dadas as exigências a que estão submetidos os programas de pósgraduação e também os critérios de originalidade e ineditismo estabelecidos pelo periódico.

\section{Agradecimentos}

Ao Conselho Nacional de Desenvolvimento Científico e Tecnológico (CNPq) e ao Programa de Capacitação Institucional (PCI) do Museu Paraense Emílio Goeldi - MPEG/MCTI pela concessão de bolsa a uma das autoras deste artigo. À equipe editorial do Boletim do Museu Paraense Emílio Goeldi pelo apoio prestado para a realização da pesquisa.

\section{Referências}

ALENCAR, Daniele Alves de; BELTRÃO, Jimena Felipe. Tradição e contribuição de um periódico científico na Amazônia: o caso do Boletim do Museu Paraense Emilio Goeldi. Ciências Humanas no período de 1990 a 2015. Belém, 2016. 6 p. Plano de trabalho entregue ao Programa de Capacitação Institucional do PCI/MPEG.

ALMEIDA, Fernando Ozorio de; ROCHA, Bruna. Uma tradução do clássico de DeBoer e Lathrap: "o fazer e o quebrar da cerâmica Shipibo-Conibo". Boletim do Museu Paraense Emílio Goeldi. Ciências Humanas, Belém, v. 11 , n. 1, p. 315-339, jan./abr. 2016.

ASSOCIAÇÃO BRASILEIRA DE NORMAS TÉCNICAS. NBR 6022: informação e documentação: artigo em publicação periódica científica impressa: apresentação. Rio de Janeiro, 2003.

BELTRÃO, Jimena Felipe; SILVA, Taíse da Cruz. Trajetória e novos rumos das políticas editoriais do Boletim do Museu Paraense Emílio Goeldi.

Ciências Humanas. Ponto de Acesso, Salvador, v. 12, n. 3, p. 28-50, dez. 2018. DOI: http://dx.doi.org/10.9771/rpa.v12i3.26920.

BELTRÃO, Jimena Felipe; SILVA, Taíse da Cruz; ALENCAR, Daniele Alves; LOPES, Arlene Cristina Borges. Boletim do Museu Paraense Emílio Goeldi. Ciências Humanas: uma análise bibliométrica no Período de 2006 a 2015. Revista $A C B$, Florianópolis, v. 24, n. 1, p. 177-198, dez./mar. 2019. Disponível em: https://revista.acbsc.org.br/racb/article/view/1532. Acesso em: 11 ago. 2020. 
BELTRÃO, Jimena Felipe; SILVA, Taíse da Cruz. De um sistema nacional à adoção de padrões internacionais: por uma nova norma bibliográfica.

Biblionline, Paraíba, v. 15, n. 1, p. 136-147, jun. 2019. DOI:

https://doi.org/10.22478/ufpb.1809-4775.2019v15n1.43743.

BENCHIMOL, Alegria; PINHEIRO, Lena Vania Ribeiro. O Boletim do Museu Paraense Emílio Goeldi: trajetória e aspectos históricos dos primeiros 20 anos (1894-1914) na Amazônia e no cenário internacional. In: ENCONTRO NACIONAL DE PESQUISA EM CIÊNCIA DA INFORMAÇÃO, 15., 2014, Belo Horizonte. Anais [...]. Belo Horizonte: ANCIB, 2014. p. 4271-4292.

BENCHIMOL, Alegria; ARRUDA, Maria Izabel Moreira; SILVA, Taíse da Cruz. Boletim do Museu Paraense Emílio Goeldi: do impresso ao eletrônico. Informação e Sociedade: estudos. João Pessoa, v. 26, n. 3, p. 81-93, set./dez. 2016.

BOMFÁ, Claudia Regina Ziliotto; MOCELLIN, Elis Regina; TRCEZIAK, Dorzeli Salete; FREITAS, Maria do Carmo Duarte. Acesso livre à informação científica digital: dificuldades e tendências. Transiformação, Campinas, v. 20, n. 3, p. 309-318, set./dez. 2008.

BUFREM, Leilah Santiago. Política editorial universitária por uma crítica à pratica. Perspectiva em Ciência da Informação, Belo Horizonte, v. 14, n. 1, p. 23-36, jan./abr. 2009. DOI: http://dx.doi.org/10.1590/S141399362009000100003.

CALVERT, Philip J.; ZENGZHI, Shi. Quality versus quantity: contradictions in LIS journal publishing in China. Library Management, Bingley, v. 22, n. 4/5, p. 205-211, June 2001.

COORDENAÇÃO DE APERFEIÇOAMENTO DE PESSOAL DE NÍVEL SUPERIOR (CAPES): WebQualis. 2013-2016. Disponível em:

https://sucupira.capes.gov.br/sucupira/public/consultas/coleta/veiculoPubl icacaoQualis/listaConsultaGeralPeriodicos.jsf. Acesso em: 13 jun. 2017.

COSTA, Sely Maria de Souza; GUIMARÃES, Luísa Veras de Sandes. Qualidade de periódicos científicos eletrônicos brasileiros que utilizam o Sistema Eletrônico de Editoração de revista (SEER). Informação e Informação, Londrina, v. 15, p. 75-93, jan./abr. 2010. Edição especial.

FERREIRA, Sueli Mara Soares Pinto. Critérios de qualidade para as revistas científicas em comunicação. In: ; TARGINO, Maria das Graças (org.). Preparação de revistas científicas: teoria e prática. São Paulo: Reichmann\& Autores Ed., 2005. p. 269-293. 
FIGUEIREDO, Élida Moura de. A produção científica da área de zoologia do Museu Paraense Emílio Goeldi, do período de 1988 a 2006. Belém: MPEG, 2007. Relatório final do subprojeto.

GUMIEIRO, Katiucia Araújo; COSTA, Sely Maria de Souza. O uso de modelos de negócios por editoras de periódicos científicos eletrônicos de acesso aberto. Perspectivas em Ciência da Informação, Belo Horizonte, v. 17, n. 4, p.100-122, out./dez. 2012.

GRUSZYNSKI, Ana Cláudia; GOLIN, Cida; CASTEDO, Raquel. Produção editorial e comunicação científica: uma proposta para edição de revistas científicas. Revista da Associação Nacional dos Programas de PósGraduação em Comunicação-E-compós, Brasília, v. 11, n. 2, p. 1-17, maio/ago. 2008.

HOUAISS, Antônio; VILLAR, Mauro de Salles; FRANCO, Francisco Manoel de Mello. Dicionário Houaiss da Língua Portuguesa. Rio de Janeiro: Objetiva, 2004.

MERLO, Franciele; KONRAD, Glaucia Vieira Ramos. Documento, história e memória: a importância da preservação do patrimônio documental para o acesso à informação. Informação e Informação, Londrina, v. 20, n. 1, p. 26-42, jan./abr. 2015.

MUELLER, Suzana Pinheiro Machado. O periódico científico. In: CAMPELLO, Bernadete Santos; CENDÓN, Beatriz Valadares; KREMER, Jeannette Marguerite (Org.). Fontes de informação para pesquisadores e profissionais. Belo Horizonte: UFMG, 2000a. p. 73-95.

- A ciência, o sistema de comunicação científica e a literatura científica. In: CAMPELLO, Bernadete Santos; CENDÓN, Beatriz Valadares; KREMER, Jeannette Marguerite (org.). Fontes de informação para pesquisadores e profissionais. Belo Horizonte: UFMG, 2000b. p. 21-34.

OLIVEIRA, Érica Beatriz. Produção científica nacional na área de geociências: análise de critérios de editoração, difusão e indexação em bases de dados. Ciência da Informação, Brasília, v. 34, n. 2, p. 34-42, maio/ago. 2005.

PACKER, Abel L. Os periódicos brasileiros e a comunicação da pesquisa nacional. Revista USP, São Paulo, n. 89, p. 26-61, mar./maio 2011. Disponível em:

http://www.revistas.usp.br/revusp/article/view/13868/15686. Acesso em: 21 dez. 2016. 
PADILHA, Maria Itayra; BRÜGGEMANN Odaléa; COSTA, Roberta; SILVA, Denise Maria Guerreiro Vieira da; VARGAS, Mara Ambrosina; ANDRADE, Selma Regina; MONTICELLI, Marisa. A internacionalização do conhecimento e o aumento da qualidade e da visibilidade dos periódicos brasileiros. Texto \& Contexto Enfermagem, Florianópolis, v. 23, n. 3, p. 515-516, jul./set. 2014.

PAIVA, Eliane Bezerra; RAMALHO; Francisca Arruda; CARVALHO, Ediane Toscano Galdino de. Informação e memória indígena no Boletim do Museu Paraense Emílio Goeldi. Ciências Humanas. In: ENCONTRO NACIONAL DE PESQUISA EM CIÊNCIA DA INFORMAÇÃO, 16., João Pessoa, PB. Anais [...]. João Pessoa, PB, 2015.

PINHEIRO, Lena Vania Ribeiro; BRÄSCHER, Marisa; BURNIER, Sonia. Ciência da Informação: 32 anos (1972-2004) no caminho da história e horizontes de um periódico científico brasileiro. Ciência da Informação, Brasília, v. 34, n. 3, p. 23-75, set./dez. 2005.

RODRIGUES, Rosângela Schwarz; OLIVEIRA, Aline Borges de. Periódicos científicos na América Latina: títulos em acesso aberto indexados no ISI e SCOPUS. Perspectivas em Ciência da Informação, Belo Horizonte, v. 17, n. 4, p. 77-99, out./dez. 2012.

SABADINI, Aparecida Angélica Zoqui Paulovic; SAMPAIO, Maria Imaculada Cardoso; KOLLER, Sílvia Helena. Preparando um artigo científico. In: - Publicar em psicologia: um enfoque para a revista científica. São Paulo: Associação Brasileira de Editores Científicos de Psicologia, 2009. p. $117-161$.

SABADINI, Aparecida Angélica Zoqui Paulovic; SAMPAIO, Maria Imaculada Cardoso;NASCIMENTO, Maria Marta. Preparando um periódico científico. In:SABADINI, Aparecida Angélica Zoqui Paulovic; SAMPAIO, Maria Imaculada Cardoso;KOLLER, Sílvia Helena. Publicar em psicologia: um enfoque para a revista científica. São Paulo: Associação Brasileira de Editores Científicos de Psicologia, 2009. p. 35-73.

SCIENTIFIC ELECTRONIC LIBRARY ONLINE (Scielo). Critérios, políticas e procedimentos para admissão e a permanência de periódicos científicos na Coleção SciELO Brasil. São Paulo, 2014. 30 p.

SOUSA, Kleber Romano de. Publicação científica seriada da Amazônia: o Boletim do Museu Paraense Emílio Goeldi-trajetória e impacto de 1984 a 2005. Belém: MPEG, 2006. Relatório final do subprojeto.

SPINAK, Ernesto. Ética editorial e o problema do autoplágio. SciELO em Perspectiva, 11 nov. 2013. Disponível em: 
http://blog.scielo.org/blog/2013/11/11/etica-editorial-e-o-problema-doautoplagio/\#.WQyK1tIrKUn. Acesso em: 5 maio 2017.

STUMPF, Ida Regina Chitto. Avaliação pelos pares nas revistas de comunicação: visão dos editores autores e avaliadores. Perspectivas em Ciência da Informação, Belo Horizonte, v. 13, n. 1, p. 18-32, jan./abr. 2008.

TRZESNIAK, Piotr. A estrutura editorial de um periódico científico. In:

SABADINI, Aparecida Angélica Zoqui Paulovic; SAMPAIO, Maria Imaculada Cardoso; KOLLER, Sílvia Helena (org.). Publicar em psicologia: um enfoque para a revista científica. São Paulo: Associação Brasileira de Editores Científicos de Psicologia, 2009. p. 87-102. 